\title{
Comparison of Tramadol and Dexamethasone as an adjuvant to Bupivacaine in Supraclavicular brachial plexus block: A Randomised Comparative Study In Patients undergoing Elective Upper limb surgeries
}

\author{
Sudha Shah *1, Bharat Shah ${ }^{2}$, Chameli Deb ${ }^{3}$.
}

${ }^{* 1}$ Professor, Department of Anesthesia, Parul Institute of M edical Sciences and Research, Vadodara, Gujarat, India

2 Dean/Professsor, Department of Anesthesia, B.J Medical College, Ahmedabad, Gujarat, India.

${ }^{3}$ Assistant Professor, Department of anesthesia, B.J medical college, Ahmedabad, Gujarat, India.

\section{ABSTRACT}

Background: Supraclavicular nerve block is a good alternative to general anesthesia for upper limb surgery. This avoids the untoward effects of general anesthetic drugs and upper airway instrumentation. It achieves complete muscle relaxation, intraoperative hemodynamic stability, and postoperative analgesia.

Objectives: To compare the postoperative analgesia following supraclavicular brachial plexus block with Tramadol or Dexamethasone as an adjuvant to bupivacaine in elective upper extremity surgery.

Materials and Methods: Total 60 patients of ASA I and II undergoing upper extremity surgery under brachial plexus block with Bupivacaine were randomly divided in to two groups; group A received Tramadol $(2 \mathrm{mg} / \mathrm{kg})$ and group B received Dexamethasone $(0.15 \mathrm{mg} / \mathrm{kg}$ ) as an adjuvant to Bupivacaine. The duration of postoperative analgesia was recorded in both groups using pain VAS score which was determined by maximum VAS score of 8-10 and when patient demands for additional analgesia.

Results: The mean duration of postoperative analgesia in the Dexamethasone group was $1023.87-+161.01$ minutes while in the tramadol group it was $454.47+44.29$ minutes.

Conclusion: Dexamethasone with local anaesthetic prolongs postoperative analgesia significantly longer than Tramadol $(\mathrm{P}<0.05)$ when used as admixture to local anaesthetic in brachial plexus block in upper extremity surgery.

KEY WORDS: Dexamethasone, Tramadol, Bupivacaine.

Address for correspondence: Dr. Sudha shah Professor, Department of Anesthesia, Parul Institute of M edical Sciences and Research, Vadodara, Gujarat, India. E-M ail: sudhashah11111@gmail.com

\begin{tabular}{|c|c|c|}
\hline \multicolumn{3}{|c|}{ Online Access and Article Informtaion } \\
\hline \multirow{2}{*}{$\begin{array}{c}\text { Quick Response code } \\
\text { Dol: } 10.16965 \text { /ijims.2016.131 }\end{array}$} & \multicolumn{2}{|c|}{$\begin{array}{l}\text { International Journal of Integrative Medical Sciences } \\
\text { www.imedsciences.com }\end{array}$} \\
\hline & $\begin{array}{l}\text { Received: 13-06-2016 } \\
\text { Reviewed: 13-06-2016 }\end{array}$ & $\begin{array}{l}\text { Accepted: } 20-06-2016 \\
\text { Published: 30-06-2016 }\end{array}$ \\
\hline Source of Funding: Self & \multicolumn{2}{|c|}{ Conflicts of interest: None } \\
\hline
\end{tabular}

\section{BACKGROUND}

Regional block techniques avoid the unwanted effects of the anaesthetic drugs used during general anaesthesia and hemodynamic stress during laryngoscopy and intubation. These techniques are specially beneficial for patients with various cardiorespiratory comorbities. Brachial plexus block is one of them, a popular and widely employed regional nerve block technique for perioperative anesthesia and analgesia for surgery of the upper extremity.

Different drugs have been used as adjuvants with 
local anesthetics in brachial plexus block to achieve quick, dense and prolonged block $[1,2]$. Drugs like Morphine, Pethidine, Clonidine, Dexmeditomidine, Butorphanol, Midazolam are commonly used along with local anesthetics for this purpose. Since Morphine, Pethidine, Butorphanol are associated with side effects like heavy sedation, respiratory depression and psychomimmetic effects, drugs with minimal side effects are always looked for [3].

Tramadol and Dexamethasone are selected as adjuvants to local anesthetics in brachial plexus block in this study because respiratory depression is not a major problem with their use. Tramadol has been used as an adjunct to local anesthetic in axillary brachial plexus block and also in caudal anesthesia to extend the duration of postoperative analgesia [4-6]. Steroids have nerve block prolonging effects. They block the nociceptive impulse transmission along the myelinated C fibres [7]. Tramadol is an analgesic with mixed $\mu$ opioid and non opioid activity. It inhibits the reuptake of nor-epinephrine (NE) and serotonin from the nerve endings and potentiates the effect of local anesthetics when mixed together in peripheral regional nerve block. It has less respiratory depressant effect due to weak $\mu$ receptor affinity [8].

\section{MATERIALS AND METHODS}

This is a prospective, randomized, double blind study of 60 patients ( 30 patients in each group) of American Society of Anaesthesiologists (ASA) physical grade I- II, aged between $20-50$ years, undergoing upper extremity surgery (elbow, forearm and hand) under supraclavicular brachial plexus block at BJ Medical college and attached Civil hospital, Ahmedabad, Gujarat from 1997-1999 .

Exclusion Criteria: ASA III-IV, Patient refusal, uncooperative patient, local pathology or deformity, coagulopathy, history of allergy to local anaesthetic, tramadol or dexamethasone, convulsive disorders, severe neurologic disorders, patients with cardiac, respiratory, hepatic and renal disease. Pre-anesthetic check up of the patients was done and Patients were randomly allocated by chit and box method to one of the two groups of 30 patients each. Group A received $0.5 \%$ Bupivacaine $2 \mathrm{mg} / \mathrm{kg}$ with
Tramadol $2 \mathrm{mg} / \mathrm{kg}$ and group B received 0.5\% Bupivacaine $2 \mathrm{mg} / \mathrm{kg}$ with Dexamethasone $0.15 \mathrm{mg} / \mathrm{kg}$. normal saline added to make total volume $30 \mathrm{ml}$.

Fasting status, consent. PAC checked, and intravenous access secured. Patients did not receive any premedication. The patient was placed in the supine position, with the head turned away and the ipsilateral arm adducted. The interscalene groove and mid-point of the clavicle and subclavian artery were identified. After aseptic preparation of the area, at a point 1.5 to $2.0 \mathrm{~cm}$ posterior to midpoint of the clavicle a skin wheal was raised with a local anaesthetic (lignocaine2\% plain). Next, a 22G, $50 \mathrm{~mm}$ "short beveled" needle was passed through the same point in a caudal, slightly medial and posterior direction, until either a paresthesia was elicited or the first rib was encountered. If the first rib was encountered, the needle was moved over the first rib until a paresthesia was elicited either in the hand or arm. After eliciting paresthesia and negative aspiration of blood, the study medication was injected.

After performance of nerve block patients were evaluated for onset of sensory block every 1 minute. The sensory block was assessed by touch \& relief of fractured pain is present and was used for pin prick with 25 gauge needle.

Heart rate, non-invasive blood pressure, SPO2 $\&$ sedation score were measured every 5 minutes during first 30 minutes and thereafter half hourly till the end of procedure. Postoperatively heart rate, noninvasive blood pressure, pain and sedation scores were recorded at $0,30 \mathrm{~min}, 1 \mathrm{hrs}, 3 \mathrm{hrs}, 6 \mathrm{hrs}, 12$ hrs , $18 \mathrm{hrs}$. Sensory and motor block were assessed as follows:

\section{SENSORY BLOCK:}

0 Sharp pain.,

1 Touch sensation only.

2 No sensation.

\section{MOTOR BLOCK: ( modified bromage scale)}

0 no block - total arm and forearm flexion

1 partial block - total forearm and partial arm flexion

2 almost complete block - inability to flex the arm and decreased ability to flex the forearm. 
Sudha Shah et al. Comparison of Tramadol and Dexamethasone as an adjuvant to Bupivacaine in Supraclavicular brachial plexus block: A Randomised Comparative Study In Patients undergoing Elective Upper limb surgeries.

3 total block - inability to flex both the arm and forearm

Sedation was assessed using a four point scale 1 Awake and alert.

2 Drowsy but responsive to command.

3 Very drowsy but responsive to pain.

4 Unresponsive

The surgery was allowed to proceed when complete anesthesia was achieved. The duration of surgery in each case was noted.

Postoperative follow up was carried out in the recovery and postoperative ward. The duration of analgesia was noted according to the 0-10 visual analogue scale (VAS) for pain at 0,30 min. , 1 hour , 3 hour , 6 hour , 9 hour , 12 hour , 18 hours.

VAS score 0 and 8-10 were taken as no pain and worst pain perceived, respectively. The duration of analgesia was determined till the existence of good analgesia (VAS $=5-7$ ).

Patients were then rescued with additional analgesics on demand.

The duration of motor block was assessed postoperatively by asking patient to move their fingers and to see whether they were able to raise the hand or not. This time was recorded and taken as cessation of motor block effect.

None of the patients were routinely sedated or given extra analgesics; until they started complain of pain.

If any side effects related to the technique or drug such as nausea, vomiting, respiratory depression, pneumothorax occurred they were recorded and treated accordingly. The patient characteristics (age, sex, weight), duration of onset of sensory/motor block, duration of analgesia were recorded.

The comparison between the two groups with respect to demographic variables was done by unpaired t-test. Intraoperative H.R., BP,RR, SPO2 was analysed by using unpaired t-test. The onset and duration of sensory and motor blocks were compared between two groups using unpaired t-test. . P value $\measuredangle 0.05$ was considered significant.

\section{RESULTS}

The patient's characteristics (Table 1-3) in two
Table 1: Age wise Distribution.

\begin{tabular}{|c|c|c|}
\hline Characteristic & $\begin{array}{c}\text { Tramado* } \\
\text { (Group A) }\end{array}$ & $\begin{array}{c}\text { Daxamethasone* } \\
\text { (Group B) }\end{array}$ \\
\hline Mean Age (yr) & 33.53 & 34.36 \\
\hline Standard Deviation & 7.49 & 7.79 \\
\hline
\end{tabular}

* Age in year

Table 2: Sex wise Distribution.

\begin{tabular}{|c|c|c|}
\hline Sex & Group A & Group B \\
\hline Male & 25 & 25 \\
\hline Female & 5 & 5 \\
\hline Total & $\mathbf{3 0}$ & $\mathbf{3 0}$ \\
\hline
\end{tabular}

study groups were similar. The age of the patient in both group ranged from 20 to 50 years. M ean age was 33.53 years for group $A$ and 34.36 year for group $B$.

The sex distribution in two groups were also similar. The mean body weight $(\mathrm{kg})$ in group $A$ group B were 59.83 and 59.96 respectively. The mean onset of motor block following the brachial plexus block in group A was 13.07 minutes and 12.93 minutes group $B$. The difference of onset of motor block in two groups was not statistically significant $(P>0.05)$.

Table 3: Body Weight Distribution.

\begin{tabular}{|l|c|c|}
\hline \multicolumn{1}{|c|}{ Characteristic } & Tramadol* $^{*}$ & Dexamethasone* \\
\hline vime Mean & 59.83 & 59.96 \\
\hline Standard Deviation & 4.77 & 5.3 \\
\hline
\end{tabular}

* weight in $\mathrm{kg}$.

The sensory block was achieved in mean 18.20 minutes in group $A$ and 14.83 minutes in group $B$. The difference in onset of sensory block in two groups was statistically significant ( $P \varangle 0.05)$. The mean duration of surgery was 53.5 minutes in group $A$ and 53.0 minutes in group $B$. Statistical test revealed the difference was not significant between two groups $(P>05)$.

The mean duration for the motor block was 356.10 minutes in I group $A$ and 513.17 minutes in group $B$. The difference in duration of motor block in two group was significant statistically $(P<05)$.

The mean duration of analgesia in group $A$ was 454.47 minutes, whereas in group $B$ it was 
1023.87 minutes. This showed significant statistical difference $(P<.05)$ in the duration of analgesia between two groups.

Severity of pain at first analgesic requirement in group A was 6.63 and in group B was 4.77 as recorded on VAS scale which was highly significant.

Our Comparative Study between Tramadol and Dexamethasone as an adjuvant to Bupivacaine.

Table 4: Comparative Study between Two Study Groups.

\begin{tabular}{|c|c|c|c|c|c|}
\hline Characteristic & $\begin{array}{l}\text { Study } \\
\text { Groups }\end{array}$ & Number & Mean & $\begin{array}{l}\text { Standard } \\
\text { Deviation }\end{array}$ & P-Value \\
\hline \multirow{2}{*}{$\begin{array}{l}\text { Onset of motor block } \\
\text { in Minutes }\end{array}$} & A & 30 & 13.07 & 1.36 & \multirow{2}{*}{0.7751} \\
\hline & $B$ & 30 & 12.93 & 2.15 & \\
\hline \multirow{2}{*}{$\begin{array}{l}\text { Onset of sensory block } \\
\text { in minutes }\end{array}$} & A & 30 & 18.2 & 1.47 & \multirow{2}{*}{0} \\
\hline & $B$ & 30 & 14.83 & 2.61 & \\
\hline \multirow{2}{*}{$\begin{array}{l}\text { Duration of surgery in } \\
\text { minutes }\end{array}$} & A & 30 & 53.5 & 10.16 & \multirow{2}{*}{0.8601} \\
\hline & $B$ & 30 & 53 & 11.64 & \\
\hline \multirow{2}{*}{$\begin{array}{l}\text { Regression of motor } \\
\text { Block in minutes }\end{array}$} & $\bar{A}$ & 30 & 356.1 & 54.81 & \\
\hline & B & 30 & 513.17 & 75.09 & \\
\hline \multirow{2}{*}{$\begin{array}{c}\text { Total analgesia } \\
\text { duration in minutes }\end{array}$} & A & 30 & 454.47 & 44.29 & \\
\hline & B & 30 & 1023.87 & 161.01 & \\
\hline \multirow{2}{*}{$\begin{array}{l}\text { Severity of pain at first } \\
\text { analgesic requirement }\end{array}$} & A & 30 & 6.63 & 1 & \\
\hline & $B$ & 30 & 4.77 & 0.82 & \\
\hline
\end{tabular}

\section{DISCUSSION}

Brachial plexus block serves as sole anaesthetic technique to facilitate painless upper limb surgery. It provides an excellent alternative for patients who are at high risk for general anaesthesia. Various approaches have been described of which the classical supraclavicular approach is most suited for the whole of upper limb surgeries as it blocks all the branches of brachial plexus.

Longer acting local anaesthetics have been used for brachial plexus block. But still there are certain drawbacks that limits their extended use. These are: time taken to establish the block and inadequate post operative analgesia.Various studies have investigated several adjuncts that prolong the duration of analgesia.

Tramadol has been used as analgesic agent and as adjunct in intrathecal and epidural route. But the mechanism of action in peripheral nerve blocks is highly unclear. Tramadol is an analgesic with mixed mu opiod and nonopiod activity. It inhibits the reuptake of nor-epinephrine and serotonin from the nerve endings and it is supposed to potentiate the effect of local anesthetics when mixed together Dexamethasone is a steroid. Steroids have nerve block prolonging effects. Mechanism of action is not clear. But it is suggested from a number of studies that they block the nociceptive impulse transmission along unmyelinated $C$ fibres. They may also have an action on potassium channels causing hyperpolarisation and blocking nerve conduction. Johannson $A$ et al (1990) concluded that local corticosteroid application blocks transmission in normal noceceptive $C$ fibres [6].

In the present study we compared the effects of Tramadol $2 \mathrm{mg} / \mathrm{kg}$ added to $0.5 \%$ bupivacaine and effects of dexamethasone $0.15 \mathrm{mg} / \mathrm{kg}$ added to $0.5 \%$ bupivacaine $(2 \mathrm{mg} / \mathrm{kg}$ ) in supraclavicular brachial plexus block, in terms of onset and duration of sensory analgesia and motor block and side effects.

In this study the patient characteristics (age, sex and weight) were similar in both groups. The average duration of the surgeries in the both groups were also similar.

We used Bupivacaine in dose of $2 \mathrm{mg} / \mathrm{kg}$ in this study as used by Shrestha BR et al (2007) [12].

Tramadol was added in $2 \mathrm{mg} / \mathrm{kg}$ dose in our study - Kapral S et al (1999) added tramadol in total dose of $100 \mathrm{mg}$ and S. Mannion et al (2004) used tramadol in dose of $1.5 \mathrm{mg} / \mathrm{kg}$ as an adjunct $[9,22]$.

In present study dose of dexamethasone is 0.15 $\mathrm{mg} / \mathrm{kg}$. Ali M ovafegh et al (2006), Shrestha BR et al ( 2007 ) and K. C . Cummings et al ( 2011)used dexamethasone in dose of total 8 $\mathrm{mg}$ as an adjuvant [14-16].

Onset of M otor and Sensory Block: In present study, There was no significant difference in onset time. $(p>0.05)$ of motor block but onset of sensory block was significantly prolonged in Group A. These results are consistent with the studies of Shrestha BR et al ( 2007 ) [12].

The onset of motor block was faster than the sensory block in either of the group in this study. As described by Winnie in 1977 the outer motor fibers are blocked earlier than the sensory fibers which are situated deeper in the brachial plexus at the level of trunk and division [18]. 
Olfa Kabaachi (2009) noted that addition of Tramadol was associated with some delay in onset [19-20]. Dan J. Kopacz et al (2003) concluded that onset time was reduced and the duration of analgesia increased on addition of dexamethasone [7].

Duration of Motor Block and Sensory Analgesia: Our study found that the total duration of analgesia following the brachial plexus block in the group B was significantly higher than in group A. The Duration of analgesia with Tramadol in brachial plexus block in the study by Chattopadhya, Mitra et al was $410.1 \pm 95.1$ minutes.

The regression time of the motor block in the postoperative period was studied. In group $A$ the mean duration of return of the motor function was after 356.10 minutes and in group $B$ it was 513.17 minutes after the block was performed. The difference in the regression time of the motor block was found to be statistically significant $(P<05)$. Prolonged regression time may cause limitation of the neurological evaluation of the extremity in selected cases. De Jong et al studied the motor function returned after nerve block and found the motor function returns before pain perception [22].

Total duration of analgesia was determined by the intolerable pain (VAS, 8-10). This was regarded as the end poin of analgesia during the study. The difference in the severity of pain at first analgesic requirement of analgesia was significant between both group. The present study showed that the severity of pain at the requirement of analgesia was significantly lower $(p \varangle 0.001)$ in group $B$ compared with group $A$.

Kapral S et al (1999) evaluated the effect of tramadol added to mepivacaine $1 \%$ in axillary brachial plexus block. Patients received either $40 \mathrm{~mL}$ of mepivacaine $1 \%$ with $2 \mathrm{~mL}$ of isotonic sodium chloride solution (Group $A, n=20$ ); 40 $\mathrm{mL}$ of mepivacaine $1 \%$ with $100 \mathrm{mg}$ of tramadol (Group B, $n=20$ ); or $40 \mathrm{~mL}$ of mepivacaine $1 \%$ with $2 \mathrm{~mL}$ of isotonic sodium chloride solution and $100 \mathrm{mg}$ of tramadol i.v. (Group C, $\mathrm{n}=20$ ). Sensory block, motor block, and hemodynamics were recorded before and 5, 10, 30, 60, 120, 180, and $360 \mathrm{~min}$ after local anesthetic injection. Duration of sensory and motor block was significantly longer $(P<0.01 ; P<0.05)$ in Group Int J Intg M ed Sci 2016;3(6):321-26. ISSN 2394 - 4137
B (299 H/- 84 and $259+/-76$ min) than in Group A (194 $+/-35$ and $181+/-24 \mathrm{~min}$ ) and Group C (187 $+/-35$ and 179 H- $16 \mathrm{~min}$ ) [23].

Ali Movafegh et al (2006) concluded that the addition of dexamethasone to lidocaine 1.5\% solution in axillary brachial plexus block prolongs the duration of sensory and motor block [3].

Shrestha BR et al (2007) conducted a study, comparison between Tramadol and Dexamethasone as an adjunct to bupivacaine $0.5 \%$ in supraclavicular brachial plexus block. They concluded results similar to our study [18]. Shrestha BR et al (2007) also observed the degree of pain measured at first analgesic request was lower in Dexamethasone group in comparision to Tramadol group.

So our results are consistent with the previous studies. As noted by Chattopadhya $S$ et al (2007) duration of analgesia in Tramadol group was $410 \pm 95.1$ min, Vieira (2010) found that mean sensory block time in dexamethasone and bupivacaine group was 1457 min [4,22]. The present study showed a significant prolongation of sensory analgesia with addition of dexamethasone $0.15 \mathrm{mg} / \mathrm{kg}$ as compared to tramadol addition which result in less prolongation of analgesia.

Effect on Vital Parameters and Side Effects: Antonucci S et al ( 2001) carried out a study investigating the effects of tramadol $100 \mathrm{mg}$, sufentanil $20 \mathrm{mg}$ and clonidine $1.5 \mathrm{mg} \mathrm{kg}{ }_{1}$, combined with ropivacaine $0.75 \%$, demonstrated that each adjunct similarly prolonged analgesia and anaesthesia of brachial plexus block, but that the incidence of adverse effects was less with tramadol [2]. Tramadol as an opiod agent has been found to cause bradycadia, hypotension, pruritis, respiratory depression when used as an adjunct in intrathecal route and in epidural route.But these side effects use rarely seen when used in nerve blocks.

Dexamethasone as it is a steroid agent, can cause a number of side effects when used for long duration on regular basis. But its use in nerve block is not associated with such type side effects and it has no effect on respiratory rate, $\mathrm{BP}$, heart rate etc. The present 

block: A Randomised Comparative Study In Patients undergoing Elective Upper limb surgeries.

study showed no incidences of, vomiting, hypotension, bradycardia, respiratory depression with use of Tramadol or dexamethasone neither was it associated with any intraoperative or postoperative side effect.

M ild sedation was observed in 3 patients out of 30 patients who received Tramadol. There was no incidence of any respiratory depression and the patients were easily arousable on command. So this minor degree of sedation need not be considered as a major side effect.

\section{CONCLUSION}

In conclusion, Dexamethasone at the dose of $0.15 \mathrm{mg} / \mathrm{kg}$ body weight added to $0.5 \%$ bupivacaine in supraclavicular brachial plexus block in upper limb surgeries is highly effective in prolongation of sensory analgesia and it is superior to Tramadol and provides a better post operative period for the patient free of pain without any potential side effects.Tramadol is associated with delayed onset of sensory block and less prolongation of analgesia.

\section{REFERENCES}

[1]. Bazin JE, Massoni C, Bruelle P, Fenies V, Groslier D, Schoeffler $P$. The addition of opioids to local anaesthetics in brachial plexus block: the comparative effects of morphine, buprenorphine, and sufentanil. Anaesthesia 1997;52:858-62.

[2]. Antonucci S. Adjuvants in the axillary brachial plexus block Comparison between clonidine, sufentanil and tramadol. M inervaAnestesiol 2001;67:23-7.

[3]. Ali M ovafegh, MD, Mehran Razazian, MD, Fatemeh Hajimaohamadi, MD and Alipasha Meysamie Dexamethasone Added to Lidocaine Prolongs Axillary Brachial Plexus Blockade. Anesth Analg 2006;102:263-7

[4]. Chattopadhyay S, Mitra L G. Tramadol as an adjunct for Brachial plexus block. J Anaesth Clin Pharmacol 2007;23(2):187-9.

[5]. Colombo G ,Padera R , Langer R , Kohane D S. Prolonged duration of local anaesthetic with LPSP containing bupivacaine and dexamethasone. 2005; $1 ; 75(2): 458-64$.

[6]. Johanson A, Hao J. Local corticosteroid application blocks transmission in normal nociceptive c-fibres. Acta Anesthesiologica scand 1990;34:335-8.

[7]. Dan J. Kopacz, M D, Peter G. Lacouture, PhD, Danlin Wu, PhD, Partha Nandy, PhD, Ruth Swanton, M PH and Craig Landau, MD. The Dose Response and Effects of Dexamethasone on Bupivacaine M icrocapsules for Intercostal Blockade (T9 to T11) in Healthy Volunteers. A\&A Feb 2003;96(2):576-582.

[8]. Estebe JP, Le Corre P, Clement R, Du Plessis L, Chevanne $F$, Le Verge R, Ecoffey C. Effect of dexamethasone on motor brachial plexus block with bupivacaine and with bupivacaine-loaded microspheres in a sheep model. European journal of Anaesthesiology. 2003 Apr 1;20(04):305-10.
[9]. Kapral S, Gollmann G, Walti B, Likar R, Sladen RN, Lehofer $F$. Tramadol added to mepivacaine prolongs the duration of an axillary brachial plexus blockade. Anaesthes Analg 1999;88:853-6.

[10]. Kayser V, Besson JM, Guilbaud G. Evidence for noradrenergic component in the antinociceptive effect of the analgesic agent tramadol in an animal model of clinical pain. Eur J Pharmacol 1992; 224: 83-8

[11]. K. C. Cummings III, D. E. Napierkowski, Parra-Sanchez, A. Kurz, J. E. Dalton, J. J. Brems and D. I. Sessler Effect of dexamethasone on the duration of interscalene nerve blocks with ropivacaine or bupivacaine. BJA 2011;107(3):446-453.

[12].Sherstha B R, Maharajan S K, Tabedar S, Supraclavicular block with or without dexamethasone. KUMJ 2003:1:94-95.

[13]. Winnie AP, Tay C-H, Patel KP, Ramamurthy S, Durrani Z. Pharmacokinetics of local anaesthetics during brachial plexus blocks. Anaesth analg 1977;56:85261.

[14]. Robaux S, Blunt C, Viel E, et al. Tramadol added to $1.5 \%$ M epivaciane for axillary brachial plexus block improves postoperative analgesia . Anaesth Analg 2004 April;98(4):1172-7.

[15]. Lund PC, Cwik JC, Vallesteros F. Bupivacaine - a new long acting local anaesthetic agent. A preliminary clinical and laboratory report. Anaesth Analg 1976;49:103-13.

[16]. Castillo Jenny, Curley J, Hotz J, et al. Glucocorticoids prolong rat sciatic nerve blockade in vivo from bupivacaine microspheres. Anaesthesiology 1996;85:1157-66.

[17]. Stan T, Goodman E, Cardida B, Curtis RH. Adding methylprednisolone to local anaesthetic increases the duration of axillary brachial plexus block. Reg Anaesth Pain Med 2004;29:380-1.

[18]. Shrestha BR et al comparative study between tramadol and dexamethasone as an admixture to bupivacaine. JNM A 2007;46(4):168.

[19]. de Jong RH, Wagman IH. Physiological mechanism of peripheral nerve block by local anaesthetics. Anaesthesiology 1963;24:684-7.

[20]. Partridge BL, Katz J, Bernirschke K. Functional Anatomy of brachial plexus sheath. Implications for Anaesthesia. Anaesthesiology 1987;66:743-7.

[21]. Vieira P A et al .Dexamethasone with bupivacaine increases duration of analgesia in USG guided interscalene brachial plexus blockade. Eur J Anaesthesiol.2010 Mar, 27(3):285-8.

[22]. S. Mannion et al. Tramadol as adjunct to psoas compartment block with levobupivacaine. BJA. 2005;94(3):352-6.

[23]. Olfa kaabachi et al. Tramadol as an adjuvant to lidocaine for axillary brachial plexus block. Anesth. A nalog. 2009 Jan;108(1):367-70.

How to cite this article: Sudha Shah, Bharat Shah, Chameli Deb. Comparison of Tramadol and Dexamethasone as an adjuvant to Bupivacaine in Supraclavicular brachial plexus block: A Randomised Comparative Study In Patients undergoing Elective Upper limb surgeries. Int J Intg Med Sci 2016;3(6):321-326. DOI: 10.16965/ ijims.2016.131 